\title{
Políticas educacionais e gênero: um balanço dos anos 1990*
}

\author{
Fúlvia Rosemberg $^{* *}$
}

\begin{abstract}
Resumo
Este artigo tem por objeto descrever tendências, apontar avanços e lacunas nas políticas educacionais olhadas a partir de uma perspectiva de igualdade de gênero. Pretendo, assim, contribuir para a problematização da agenda hegemônica compartilhada pelo atual governo brasileiro, pelas organizações multilaterais $e$ por segmentos importantes dos movimentos feministas, nacional e internacional.
\end{abstract}

Palavras-chave: Gênero, Política Educacional, Igualdade,

Feminismo.

* Recebido para publicação em novembro de 2001.

** Fundação Carlos Chagas e PUC-SP.

cadernos pagu (16) 2001: pp.151-197. 
Políticas educacionais e gênero

Educational Policy and Gender: an Appraisal of the Nineties

\section{Abstract}

This article intends to describe tendencies, progresses and gaps in educational policy from the perspective of gender equality. I intend to problematize the hegemonic agenda shared by the current Brazilian government, multilateral organizations and important sectors of the feminist movement, both national and international.

Key words: Gender, Educational Policy, Equality, Feminism. 
Fúlvia Rosemberg

\section{Introdução}

A década de 1990 assistiu a forte movimentação nas políticas educacionais brasileiras resultante dos desdobramentos da Constituição de 1988 e da nova conjuntura internacional. Tal movimentação traduz-se em reformas que levam ao enfrentamento de ampliar a oferta, acertar o fluxo de alunos/as, obter ganhos de qualidade e, ao mesmo tempo, restringir o uso de recursos públicos. Tais reformas não são particulares ao Brasil e à América Latina, configurando, ao contrário, um movimento internacional que vem, também, autorgando à educação a condição de estratégia fundamental para a redução de desigualdades econômicas e sociais nacionais e internacionais. ${ }^{1}$

Destacam-se entre os principais componentes das reformas da década: a promulgação da nova Lei de Diretrizes e Bases da Educação Nacional (LDB, Lei $n^{\circ}$ 9.394, aprovada em dezembro de 1996); a formulação de Parâmetros ou Referenciais Curriculares Nacionais para os diferentes níveis de ensino; a introdução de Sistemas Nacionais de Avaliação da educação básica (SAEB e ENEM) e superior (ENC); a política da avaliação e distribuição do livro didático; as regras de financiamento da educação, especialmente através da lei que criou o Fundo de Manutenção e Desenvolvimento do Ensino Fundamental e de Valorização do Magistério (FUNDEF). A avaliação do impacto de tais reformas, no plano de democratização da educação $e$ dos sentidos atribuídos à escolaridade, não angaria unanimidade nacional. Tendências progressistas entre pesquisadores/as e educadores $/ \mathrm{as}^{2}$ assinalam a subserviência do setor educacional a regras do mercado, destacando o forte viés economicista de tais

1 HADDAD, Sergio. Os bancos multilaterais e as políticas educacionais no Brasil. In: VianNA Jr., Aurélio. (ed.) A estratégia dos bancos multilaterais para o Brasil. Brasília, Rede Brasil, 1998, pp.41-52.

2 A partir deste ponto, não mais usarei a fórmula o/a, a não ser que seja necessária para precisar sentidos. 
Políticas educacionais e gênero

reformas. ${ }^{3} \mathrm{O}$ recente Fórum Mundial da Educação, realizado em Porto Alegre (outubro de 2001), reuniu um número significativo de opositores a essas tendências que vêm assumindo hegemonia a partir do "Consenso de Washington".

É neste contexto que a educação vem ocupando posição de destaque na agenda mundial para o desenvolvimento. Assim, na década de 1990, foram realizadas inúmeras conferências mundiais tratando da educação sob a égide da ONU e de suas organizações filiadas: UNESCO, UNICEF e Banco Mundial. O Brasil foi signatário dos compromissos da Conferência Educação para Todos/EFA (Conferências de Jomtien e Dakar) e ativo participante do grupo $\mathrm{EFA}$ - 9, que reúne os nove países em desenvolvimento mais populosos do mundo. O Brasil foi signatário, também, de todos os compromissos internacionais relativos à igualdade de oportunidades educacionais a mulheres e homens resultantes de acordos multilaterais firmados nas Conferências Internacionais da década de 1990, também patrocinadas pela ONU. Tais acordos enfatizam a prioridade da educação das mulheres e justificam-na como estratégia de escol no combate à desigualdade social $e$ ao subdesenvolvimento.

Documentos oficiais brasileiros vêm reiterando a posição de que o sistema educacional brasileiro está imune à discriminação contra as mulheres e de gênero ${ }^{4}$, como se atesta no trecho transcrito abaixo, um dentre muitos, retirado do informe nacional à Conferência de Dakar.

As orientações estabelecidas em Aman e Islamabad já estavam incorporadas à política educacional do governo brasileiro, especialmente aquelas referentes à importância atribuída ao treinamento, status, remuneração e motivação de professores. Por

3 Coraggio, J. L. Propostas do Banco Mundial para a educação: sentido oculto ou problemas de concepção? In: DE TOMMASI, L. et alii. (eds.) O Banco Mundial e as políticas educacionais. São Paulo, Cortez, 1996, pp.75-123.

4 Brasil. MEC/INEP. EFA 2000 Educação para todos. Avaliação do ano 2000, informe nacional, Brasília, 2000. 
Fúlvia Rosemberg

outro lado, as recomendações da V Conferência Internacional de Educação de Pessoas Adultas (Hamburgo, 1997) constituem uma preocupação central do Plano Nacional de Educação. Dos objetivos e metas estabelecidos nas conferências EFA 9, somente os relativos à priorização da educação de mulheres e meninas não foram incorporados pelo Brasil, onde este problema não se verifica. As taxas de escolarização, bem como as de sucesso escolar e de número médio de anos de escolarização, são mais altas na população feminina do que na masculina. Dando continuidade a esta tendência, a preocupação com a questão de gênero, no Brasil, terá que ser invertida. ${ }^{5}$

Ou seja, o governo brasileiro, em consonância com as organizações multilaterais e tendências hegemônicas do movimento de mulheres, interpreta que a igualdade de oportunidades de gênero no sistema educacional reduz-se a indicadores de acesso e permanência, olvidando-se de outras dimensões da educação que refletem, sustentam e criam desigualdades de gênero ${ }^{6}$ : o sistema educacional participando da formação do/a cidadão/ã; o sistema educacional como mercado de trabalho e de consumo; o sistema educacional interpondo dificuldades para o prosseguimento da escolaridade de mulheres $e$ homens pertencentes a segmentos sociais subalternos - não brancos, de zona rural, oriundos de famílias de baixa renda, das regiões Norte e Nordeste. ${ }^{7}$

${ }^{5}$ BRASIL. MEC/INEP. EFA 2000... Op.cit., pp.15-16.

${ }^{6}$ Pode-se encontrar tal posição defendida em vários textos, destacando, a título de exemplo: Articulação DE MulHeres BRAsileiras. Políticas públicas para as mulheres no Brasil: 5 anos após Beijim. Brasília, UNIFEM, Fundação FORD, 2000; BANCO Mundial (2000). Ensino secundário: relatório. www.bm.org, fev. 2001; STROMQUIST, Nelly P. Gender, equity and emancipatory education in Latin America. In: STROMQUIST, Nelly P. (org.) Gender dimensions in education in Latin America. Washington, Interamer 53, OAS, 1997; UNICEF. The girl child: an investment in the future. New York, UNICEF, 1991 (edição revista).

7 Louro, Guacira Lopes. O Corpo Educado: pedagogias da sexualidade. Belo Horizonte, Autêntica, 1999; CARVALHO, Marília P. Gênero e política educacional em tempos de incerteza. In: Hypolito, Alvaro M. \& GARDIN, Luiz A. (orgs.) 
Políticas educacionais e gênero

Este artigo tem por objeto descrever tendências, apontar avanços e lacunas nas políticas educacionais olhadas a partir de uma perspectiva de igualdade de gênero. Pretendo, assim, contribuir para a problematização da agenda hegemônica compartilhada pelo atual governo brasileiro, pelas organizações multilaterais e por segmentos importantes dos movimentos feministas, nacional e internacional.

A partir de estudos que venho realizando nos últimos anos ${ }^{8}$, tenho apontado que tais atores sociais, amparados em análises de situação muitas vezes equivocadas, e em modelo teórico pouco adequado ao sistema educacional, vêm empobrecendo, de modo convergente, a agenda de reivindicações sobre a igualdade de oportunidade de gênero na educação. ${ }^{9}$ Talvez seja possível anunciar, mesmo que timidamente ainda, que a atual agenda compartilhada unanimentemente por organizações multilaterais, governos (inclusive o brasileiro), movimento feminista/de mulheres e por parte do campo de estudos de gênero/sobre mulheres, obnubila processos de dominação de gênero na educação. Traçarei, então, um perfil da educação de homens e mulheres na educação brasileira, procurando apontar onde encontro tais pontos de inflexão para questionar a agenda hegemônica.

Neste artigo serão usados os termos: sexo, para referir-se a homens e mulheres a partir de sua identidade civil, compondo, portanto, uma variável disjuntiva; gênero, para referir-se a construções simbólicas em torno do masculino e do feminino em nossa sociedade, que acolhe e sustenta a ideologia da superioridade do masculino sobre o feminino; cor para referir-se a

Educação em tempos de incertezas. Belo Horizonte, Autêntica, pp.137-162; ROSEMBERG, Fúlvia. Educação formal, mulher e relações de gênero: um balanço preliminar da década de 1990. 2001 [no prelo].

8 Rosemberg, Fúlvia. A Escola e as diferenças sexuais. Cadernos de Pesquisa, n ${ }^{\circ}$ 15, dezembro de 1975, pp.78-85; Expansão da educação infantil e processos de exclusão. Cadernos de Pesquisa, no 107, julho de 1999, pp.7-41; Educação formal, mulher e relações de gênero... Op.cit.

9 ID., Educação formal, mulher e relações de gênero... Op.cit. 
auto classificação do/a respondente a uma das cinco alternativas de denominação propostas pelo Instituto Brasileiro de Geografia e Estatística (IBGE) - branca, preta, parda, indígena e amarela -, lembrando que a denominação "raça negra" ou "negros/as" é reservada ao subgrupo composto pelas pessoas que se declaram pretas e pardas.

Parte do artigo baseia-se na análise de dados macro, tendo privilegiado aqueles coletados e publicados pelo IBGE através das Pesquisas Nacionais para Amostra de Domicílios/PNADs. ${ }^{10}$

\section{Estatísticas educacionais}

No Brasil são três as instituições que coletam/consolidam estatísticas educacionais: o MEC (Ministério da Educação e do Desporto), através do INEP (Instituto Nacional de Estatística e Pesquisas Educacionais) e das Secretarias Estaduais de Educação, que delimita como unidade de coleta principal o estabelecimento de ensino; o IBGE que delimita como unidade de coleta o domicílio. Complementarmente, o Ministério do Trabalho, através da Relações Anuais de Informações Sociais/RAIS, também consolida informações sobre professores(as), trabalhando no mercado formal $e$ delimitando como unidade de coleta as empresas (no caso, os estabelecimentos de ensino).

Cada uma dessas instâncias, em decorrência de suas particularidades, dispõe de instrumentos específicos de coleta, define uma população específica e, portanto, apresenta resultados não obrigatoriamente coincidentes. Por exemplo, enquanto as estatísticas do IBGE referem-se a estudantes, as do MEC a matrículas; o número de matrículas e de estudantes pode não coincidir, bem como divergem as variáveis selecionadas para caracterizar uma unidade e outra.

${ }^{10}$ Os dados sobre instrução e educação coletados pelo Censo 2000 ainda não foram divulgados. Atentar que as PNADs não coletam informações sobre população rural de Rondônia, Acre, Amazonas, Roraima, Pará e Amapá, fato relembrado em cada tabela de modo simplificado. 
Políticas educacionais e gênero

As estatísticas educacionais brasileiras vêm melhorando, especialmente na atual administração federal. Recomendações internacionais (OCDE, UNESCO, UNICEF, por exemplo) vêm insistindo, nos últimos anos, juntamente com o movimento de mulheres/feminista, sobre a necessidade de desagregarem-se as estatísticas educacionais por sexo. ${ }^{11}$ Esta prática, que já vinha sendo historicamente usada pelo IBGE e pelo MEC, tem sido ampliada: por exemplo, informações sobre sexo e cor/raça foram também incluídas nos instrumentos recentes de avaliação de desempenho de alunos, tal como o Sistema de Avaliação do Ensino Básico/SAEB e no Exame Nacional de Cursos/ENC.

Dispõe-se, então, no país de um acervo rico e complexo de informações estatísticas sobre alfabetização, instrução, freqüência à escola, matrículas, conclusões de curso, tipos e qualidade de estabelecimentos, aprovação/reprovação, resultados em provas nacionais, função docente (formação), professores integrando a população economicamente ativa. Porém, a divulgação de dados desagregados por sexo, especialmente relativos aos Censos Educacionais sob a responsabilidade do INEP/MEC, é bastante precária, ficando muito aquém do rico acervo coletado.

Teme-se que tais informações sejam apenas processadas $e$ divulgadas em ocasiões especiais (por exemplo, no Dia Internacional da Mulher) tendo em vista a posição que vem sendo assumida pelo MEC de que o Brasil teria superado a desigualdade de gênero no plano educacional. ${ }^{12}$

A omissão da divulgação $e$ análise sistemática de dados desagregados por sexo é particularmente notável na educação

${ }^{11}$ BONINO, Maria. Monitorando o cumprimento dos acordos de cúpula nas áreas de educação e gênero. In: Balanço do observatório da cidadania. Rio de Janeiro, IBASE, 1999, pp.86-89.

${ }^{12}$ Uma recente iniciativa do Conselho Nacional dos Direitos da Mulher (CNDM) deve ser louvada pela exceção à precariedade de dados publicados sobre educação desagregados por sexo: trata-se do projeto Indicadores de Gênero, disponível no sítio do CNDM na Internet (www.mj.gov.br/sedh/cndm) e que incluiu um excelente levantamento sobre educação. 
infantil, no ensino superior, na pós-graduação, e nas inovações contemporâneas para melhoria do fluxo de alunos/as, tais como as classes de aceleração. Assim, estatísticas sobre ramificações do sistema regular, que podem indicar novos processos de discriminação, são pouco difundidas e, quando apresentadas, não são desagregadas por sexo e cor/raça. Deve-se notar, também, a escassez de informação sobre educação de homens e mulheres pertencentes aos povos indígenas e cigano.

Destaco, porém, um viés mais importante na sistemática de coleta, difusão e análise de dados sobre o setor educacional na perspectiva de gênero: sua centração em aspectos intra-escolares, mais particularmente, magistério e alunado. Ora, a educação, mesmo formal, extrapola os muros da escola, especialmente na contemporaneidade a partir da espetacular difusão das novas tecnologias educacionais - informática, televisão $-e$ da massificação de materiais didáticos tradicionais, tais como livros e jogos. O sistema educacional não é uma ilha: construção civil, transporte, equipamentos, vestuário, materiais didáticos de toda natureza, são alguns dos setores da economia que afetam e são afetados pela educação, especialmente após sua massificacão. Ora, informações sobre o mercado da educação, em plano nacional e internacional, sua dinâmica de relações de gênero permanecem uma grande incógnita. Perguntas que relacionem a centralidade da educação na agenda mundial, processos de expansão dos sistemas educacionais formais e não-formais, difusão de tecnologias educacionais e novas dinâmicas de gênero (poderia acrescentar de classe e raça) no mercado de trabalho $e$ no espaço doméstico, não são formuladas - este é meu argumento - também porque dados não são coletados dessa ótica. A relação inversa também é verdadeira: sem novas perguntas, novos dados dificilmente são coletados. E ficamos na mesmice de uma agenda para pesquisa e ação política elaborada em época anterior à expansão fantástica dos sistemas de ensino, de alterações na economia mundial e da expansão de novas tecnologias educacionais. Estes, a meu ver, constituem pontos cruciais a serem 
Políticas educacionais e gênero

incorporados em nova agenda de pesquisas sobre educação $e$ gênero.

Em sua ausência, tratarei, a seguir, dos indicadores educacionais e de homens e mulheres nos sistema educacional brasileiro a partir das informações disponíveis, ou seja, intraescola.

\section{Analfabetismo e alfabetização}

Apesar de ter decrescido, o índice de analfabetismo brasileiro continua alto: 26,6\% em 1985 e 15,7\% em 1999 na população de 5 anos e mais; 21,2\% em 1985 e 13,0\% em 1999 na população de 7 anos e mais. ${ }^{13}$

A comparação dos dados coletados desde o Censo de 1872 até 1999 sobre o analfabetismo masculino e feminino evidencia uma evolução quase que perfeitamente paralela, até a década de 40, quando, então, a convergência é notável (Tabela 1, gráfico 1). Os diferenciais sexuais se mantêm relativamente altos até 1940 (na ordem de 8 pontos percentuais) em detrimento das mulheres $e$ vão se reduzindo a partir de então, mesmo em se considerando que é também, a partir de 1950, que o contingente de mulheres na população geral se sobrepõe ao dos homens (possivelmente em decorrência das melhorias nas condições de parto e pós-parto).

O processo de escolarização das mulheres, mais intenso em torno de 1940, contribuiu para acentuar a redução percentual dos analfabetos no país na década de 40, constatação feita por outros pesquisadores brasileiros que, porém, atribuem-na, exclusivamente, a processos internos ao sistema escolar. ${ }^{14}$

$\mathrm{O}$ perfil do analfabetismo feminino é praticamente idêntico ao masculino: mulheres e homens provenientes de estratos de baixos rendimentos, negros/as, residindo na zona rural e vivendo

\footnotetext{
${ }^{13}$ PNADs 1985 e 1999.

${ }^{14}$ FERRARI. 1985.
} 
Fúlvia Rosemberg

no Nordeste enfrentam as mais árduas barreiras para se alfabetizarem. ${ }^{15}$

O maior acesso das mulheres à educação e seu melhor aproveitamento escolar se refletem nos índices de alfabetização. Atualmente, a porcentagem de mulheres alfabetizadas sobrepujou à dos homens: $84,7 \%$ entre as mulheres e $83,9 \%$ entre os homens na população de 5 anos e mais. ${ }^{16}$

Diferenças entre os índices de alfabetização masculino $e$ feminino são observadas apenas em função da idade: na população jovem entre 15 e 19 anos, faixa etária mais alfabetizada do país, as mulheres apresentam índices superiores aos dos homens (97,3\% e 94,7\% respectivamente); na população mais idosa (50 anos e mais), segmento menos alfabetizado ${ }^{17}$, os índices de alfabetização masculinos são superiores aos femininos: $73,1 \% e$ $68,0 \%$ respectivamente. ${ }^{18}$

Os melhores índices femininos de alfabetização entre os mais jovens podem ser explicados pelo maior acesso e melhor aproveitamento das meninas à escolaridade. Os melhores índices masculinos de alfabetização entre os mais idosos podem ser explicados como uma herança do passado, quando o acesso das mulheres à escola era mais restrito, associada à não correção no presente pela inexistência ou insuficiência de programas de

\footnotetext{
${ }^{15}$ Não foram encontrados dados desagregados por sexo sobre matrículas em cursos de educação de jovens e adultos (Censo da Educação de Jovens e Adultos). Aguardam-se os resultados do Censo 2000 para estudar-se a incidência do retorno ao analfabetismo de populações mais idosas, fenômeno pouco estudado no Brasil. ROSEMBERG, F. \& PizA, Edith. Analfabetismo, gênero e raça no Brasil. Revista USP, n ${ }^{\circ} 28,1995$, pp.110-121. Ver gráfico 1.

${ }^{16}$ PNAD 1999.

${ }^{17}$ Com exceção da faixa etária 5-7 anos.

18 PNAD 1999.
} 
Políticas educacionais e gênero

alfabetização destinados $e$ adequados à população feminina adulta e idosa. ${ }^{19}$

\section{Gráfico 1}

Porcentagem de analfabetos na população masculina e feminina de 5 anos ou mais.

Brasil, 1872 a 1999

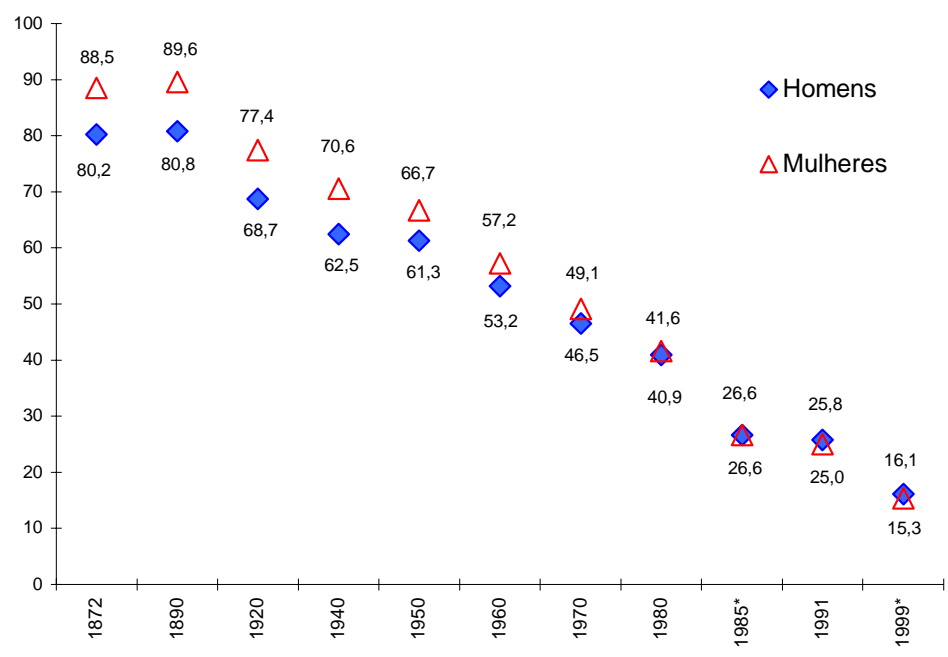

Contrariamente ao senso comum, o perfil de analfabetismo brasileiro por cor/raça diverge profundamente do perfil por sexo: negros (pretos/pardos) constituem historicamente $\mathrm{o}$ maior contingente de analfabetos, tanto em números relativos quanto em números absolutos. ${ }^{20}$ Já é tempo de que pesquisadores/as, administradores/as, militantes percebam que as lógicas dos

${ }^{19}$ Carvalho, Marilia P. de \& Di Pierro, Maria C. A escola brasileira e as desigualdades de Gênero. Cadernos do Observatório, O Observatório Educação, $\mathrm{n}^{\circ} 2$, outubro 2000.

${ }^{20}$ Rosemberg, F. \& PizA, Edith. Analfabetismo, gênero e raça... Op. cit., p.12. 
Fúlvia Rosemberg

processos de dominação de raça e gênero não são idênticas, nem sincrônicas, seja da ótica da história social, seja da ótica da trajetória de vida pessoal. ${ }^{21}$

\section{Indicadores educacionais referentes a homens e mulheres}

O diferencial entre homens e mulheres no sistema formal de ensino brasileiro não é intenso, atinge de modo diferente as diferentes idades da vida e etapas escolares, e transparece mais na progressão das trajetórias escolares do que em barreiras específicas de acesso.

As mulheres representam $51,3 \%$ da população de 5 anos e mais e $50,5 \%$ dos estudantes nesta faixa etária ${ }^{22}$, portanto, a taxa de escolaridade dos homens é ligeiramente superior à das mulheres (35,6\% e 32,5\% respectivamente na população de 5 anos e mais). Isto significa que o fenômeno da evasão escolar para a população brasileira tendo 5 anos e mais é, em termos percentuais, pouquíssimo menos freqüente entre os homens. Por outro lado, a média dos anos de estudos das mulheres ultrapassou a dos homens em 1996 e evidenciou ganhos mais expressivos na última década (Tabela 1), mantendo-se, porém, em patamar bastante baixo para ambos. ${ }^{23}$

${ }^{21}$ Rosemberg, F. Expansão da educação infantil e processos de exclusão. Op.cit. 22 PNAD 1999.

${ }^{23}$ A média dos anos de estudos apresentada pelo CNDM (2001) parece em contradição com os dados apresentados na tabela 1. Por esta razão não foram aqui incorporados. 
Políticas educacionais e gênero

Tabela 1

Anos médios de estudo na população de 5 anos e mais por ano e sexo.

Brasil.

\begin{tabular}{l|c|c|c|c|c}
\multirow{2}{*}{ Sexo } & \multicolumn{5}{|c}{ anos } \\
\cline { 2 - 6 } & 1960 & 1970 & 1980 & 1990 & 1996 \\
\hline \hline Homens & 2,4 & 2,5 & 3,3 & 5,1 & 5,7 \\
\hline Mulheres & 1,9 & 2,4 & 3,2 & 4,9 & 6,0 \\
\hline TOTAL & & 2,4 & 3,3 & 5,0 & 5,9 \\
\hline
\end{tabular}

Fontes: Censos Demográficos 1960, 1970 e 1980; PNADs 90 e 96 (apud IPEA/PNUD).

Nota: exclusive população rural da região Norte em 1990 e 1996.

A explicação da aparente contradição entre esses dois indicadores e sua evolução no período - taxa de escolaridade e anos médios de estudos - decorre de diferenciais na progressão das carreiras de homens e mulheres. Com efeito, a progressão escolar das mulheres é um pouco mais regular que a dos homens, compondo uma pirâmide educacional ligeiramente mais achatada, portanto, um pouco menos seletiva, tendência que se acentuou na década de 1990 (Tabela 2).

\section{Tabela 2}

Distribuição de estudantes de 5 anos e mais por níveis de ensino e sexo.

Brasil, 1985 e 1999.

\begin{tabular}{l|c|c|c|c}
\multirow{2}{*}{ Níveis de ensino } & \multicolumn{2}{|c|}{ Sexo /ano } & \multicolumn{2}{c}{ Sexo /ano } \\
\cline { 2 - 5 } & \multicolumn{2}{|c}{ Homens } & \multicolumn{2}{c}{ Mulheres } \\
\cline { 2 - 5 } & 1985 & 1999 & 1985 & 1999 \\
\hline \hline Pré-escolar & 7,7 & 9,4 & 7,3 & 8,6 \\
\hline Fundamental & 79,4 & 70,1 & 77,9 & 66,8 \\
\hline Médio & 8,5 & 15,0 & 10,5 & 18,2 \\
\hline Superior & 4,4 & 4,9 & 4,3 & 6,4 \\
\hline \multicolumn{1}{c|}{ Total $^{*}$} & 100,0 & 100,0 & 100,0 & 100,0
\end{tabular}

Fontes: PNADs 1985 e 1999

*Incluídos os sem informação sobre o nível escolar.

Nota: exclusive população rural da região Norte. 
O fluxo escolar apresenta estrangulamento equivalente para ambos os sexos decorrente de reprovação, de evasão/expulsão escolar, porém, o dos homens é mais acidentado. Em média, um/a brasileiro/a necessita de 10,4 anos para concluir as 8 séries do ensino fundamental, o que significa uma taxa de eficiência de $0,78 .^{24}$ Uma tradução deste indicador pode ser captada na defasagem série-idade. Tal defasagem - entre a idade ideal e a idade real para freqüentar uma determinada série escolar - pode decorrer tanto de entrada tardia no sistema, de reprovações, bem como de saídas e reentradas. Ou seja, ausência de defasagem série-idade indica melhor trajetória escolar, pois mais regular, e presença de defasagem indica acidentes no percurso, portanto, pior trajetória.

Observa-se que a defasagem série-idade é menos intensa para as mulheres que para os homens em ambos os segmentos raciais e em todos os decis de renda familiar (Gráficos 2 e 3). A comparação interracial mostra que os/as negros/as (pretos/as $e$ pardos/as) apresentam defasagem mais intensa que os/as brancos/as, e que os homens negros apresentam maior defasagem que as mulheres negras, bem como, os homens brancos apresentam maior defasagem que as mulheres brancas (Gráfico 2). Apesar dessa configuração (conhecida há muito tempo), circula, no país e fora do país, um modelo "associativista" sobre desigualdades educacionais brasileiras que não parece sustentar-se em base empírica ${ }^{25}$, assumindo que cor e sexo se associam linearmente, considerando-se, erroneamente, que meninas/ mulheres negras seriam aquelas que apresentariam piores indicadores educacionais. Algumas pesquisas já mostraram que mulheres negras, para quase todas as faixas etárias, apresentam melhores indicadores educacionais que homens negros, da mesma

${ }^{24}$ BRASIL. MEC/INEP. EFA 2000... Op.cit., p.82

${ }^{25}$ CARVAlho, M. P. de \& Di Pierro, M. C. A escola brasileira e as desigualdades de Gênero. Op. cit., pp.97-99; STROMQUIST, N. P. Gender, equity and emancipatory education in Latin America. Op. cit., pp.9-24. 
Políticas educacionais e gênero

forma que mulheres brancas apresentam melhores indicadores educacionais que homens brancos. ${ }^{26}$

Gráfico 2

Defasagem idade-série média* na faixa etária de 10 a 18 anos, segundo a raça e sexo. Brasil, 1999.



Fonte: PNAD 1999. Exclusive população rural da região Norte. Dados processados por Sergei Soares (IPEA).

* Defasagem idade-série média está definida como: idade-série-7 (em anos). Nota: com exceção da população rural da região Norte.

${ }^{26}$ BARCElOS, Luiz Cláudio. Educação e desigualdades raciais no Brasil. Cadernos de Pesquisa, n 86, agosto de 1993, pp.15-24; ROSEMBERG, Fúlvia. Subordinação de gênero e alfabetização no Brasil. Idéias, no 19, 1993, pp.125-48; SILVA, Carmen Duarte et alii. Meninas bem comportadas, boas alunas; meninos inteligentes, indisciplinados. Cadernos de Pesquisa, no 107, julho 1999, pp.207-226. 
As diferenças entre os fluxos de homens e mulheres, brancos e negros produzem pirâmides educacionais distintas: a dos brancos, homens e mulheres, é pouco mais achatada (portanto menos excludente) que a de negros, homens e mulheres; complementarmente a de mulheres, brancas e negras, é menos achatadas que a de homens de seu grupo racial (Tabela 3).

Tabela 3

Distribuição dos estudantes de 5 anos e mais, por sexo e raça segundo os níveis de ensino. Brasil, 1999.

\begin{tabular}{c|c|c|c|c}
\multirow{2}{*}{ Níveis de ensino } & \multicolumn{2}{|c|}{ Homens } & \multicolumn{2}{c}{ Mulheres } \\
\cline { 2 - 5 } & brancos & negros & brancas & negras \\
\hline \hline Pré-escolar & 9,4 & 10,3 & 8,9 & 9,3 \\
\hline Fundamental & 66,3 & 76,6 & 61,7 & 73,9 \\
\hline Médio & 16,1 & 11,2 & 19,2 & 14,1 \\
\hline Superior & 8,2 & 1,9 & 10,2 & 2,7 \\
\hline
\end{tabular}

Fonte: PNAD 1999 apud CNDM (2001).

Nota: Exclusive população rural da região Norte.

A desagregação de dados sobre defasagem série-idade por renda domiciliar e sexo apresenta resultados na mesma direção apontada para raça (Gráfico 3): para todos os decis de renda $e$ faixas etárias, as meninas e moças apresentam menor distorção série-idade média que os meninos e rapazes. Ela é mais acentuada nos decis de renda inferiores e para as pessoas de maior idade (18 anos). Nestes grupos, observamos uma importante inflexão da renda familiar pelo sexo: as moças de 18 anos pertencentes ao segundo decil de renda (portanto dentre as mais pobres) apresentam menor defasagem série/idade que os rapazes de mesma idade provenientes de famílias situando-se no quarto decil de renda. Ou seja, as moças apresentam resultados equivalentes aos rapazes situados dois decis de renda acima de seu nível econômico. 
Políticas educacionais e gênero

Gráfico 3

Defasagem idade - série-média* entre 10 e 18 anos por classe de renda (em decis) e sexo
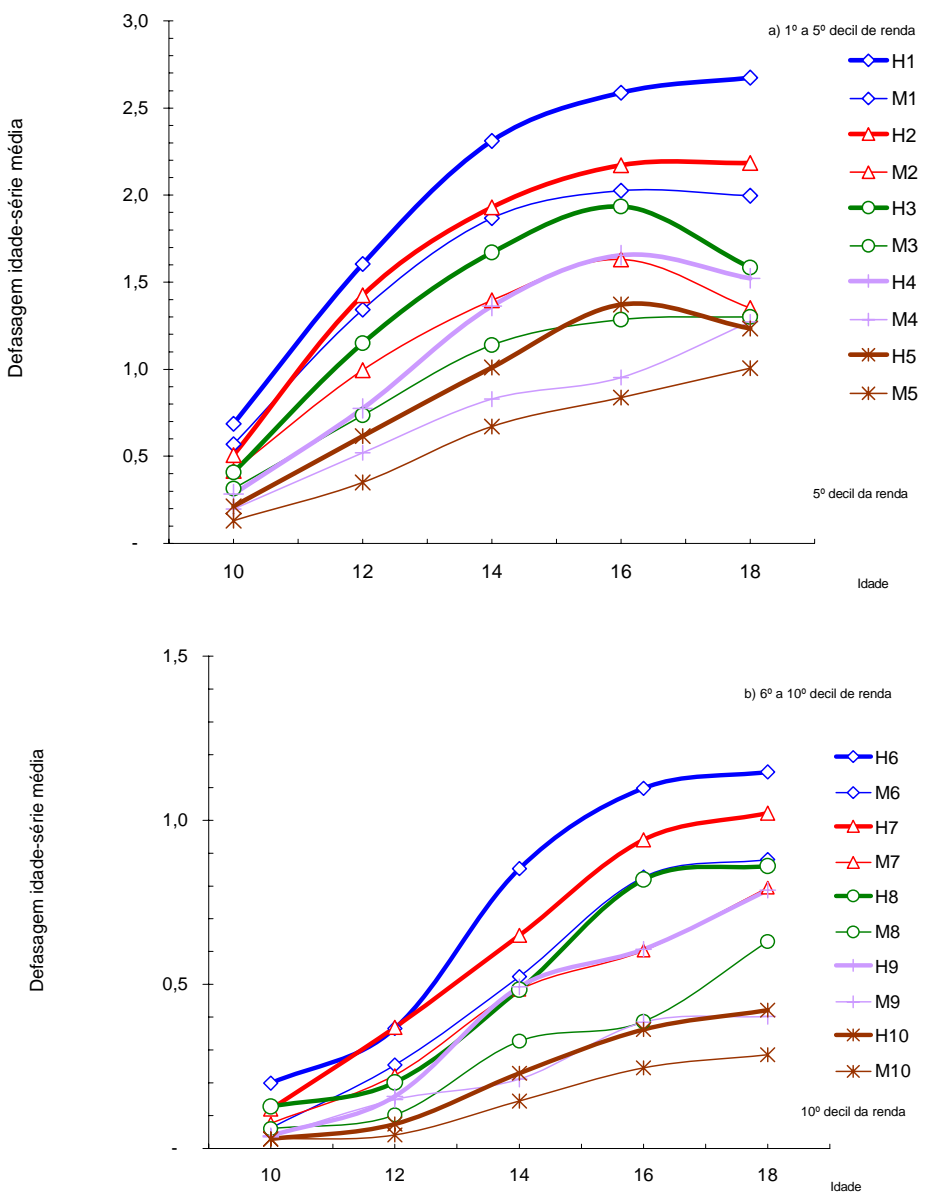

Fonte: PNAD 1999. Exclusive população rural da região Norte. Dados processados por Sergei Soares (IPEA).

* Defasagem idade-série média está definida como: Idade - série - 7 (em anos ) Nota: Para facilitar a visibilidade, a escala relativa à defasagem idade-série média não é a mesma nas figuras a $e b$. 
Conseqüentemente, em dado ano escolar, uma proporção maior de mulheres que de homens concluem os níveis fundamental, médio e superior. De acordo com informação divulgada pela então presidenta do INEP em 2000,

Entre os concluintes do ensino fundamental, $53,6 \%$ são mulheres e $46,4 \%$ homens. No ensino médio observa-se o mesmo fenômeno: $58,3 \%$ dos concluientes são mulheres $e$ $41,5 \%$ homens. A hegemonia feminina é ainda mais acentuada no ensino superior, representando $61,4 \%$ dos concluintes. ${ }^{27}$

Em suma, a proporção ligeiramente superior de estudantes entre homens, apontada no início do tópico, parece decorrer de seus passos serem mais lentos que os das mulheres, pois permanecem por mais tempo no sistema escolar para percorrerem trajeto equivalente.

Os ritmos diferentes nas trajetórias de homens e de mulheres, brancos e negros, nos níveis de ensino pré-escolar, fundamental e médio refletem-se na idade de entrada e conclusão do ensino superior, como pode-se observar nas tabelas 4 e 5 .

Estes dados podem ser controlados através da análise do perfil dos formandos que participaram, nos últimos anos, do Exame Nacional de Cursos (ENC): a porcentagem de formandos no grupo etário mais jovem (até 24 anos) é maior entre as mulheres que entre os homens em todas as carreiras consideradas (Tabela 5).

${ }^{27}$ BRASIL. MEC/INEP. EFA 2000... Op.cit., p.5. 
Políticas educacionais e gênero

Tabela 4

Distribuição dos estudantes do $1^{\circ}$ ano do ensino superior, por sexo $e$ raça segundo os grupos de idade. Brasil, 1999.

\begin{tabular}{l|c|c|c|c}
\multirow{2}{*}{ Grupos de idade } & \multicolumn{2}{|c|}{ Homens } & \multicolumn{2}{c}{ Mulheres } \\
\cline { 2 - 5 } & brancos & negros & brancas & negras \\
\hline \hline Até 18 anos & 18,3 & 15,6 & 19,7 & 16,1 \\
\hline 19 a 21 anos & 40,0 & 28,6 & 39,2 & 20,3 \\
\hline 22 a 24 anos & 14,6 & 20,3 & 10,1 & 15,5 \\
\hline 25 anos e mais & 27,1 & 35,5 & 30,9 & 48,1 \\
\hline
\end{tabular}

Fonte: PNAD 1999 apud CNDM (2001).

Nota: Exclusive zona rural da região Norte.

Tabela 5

Percentual de graduandos presentes ao ENC-99 por área, idade e sexo. Brasil, 1999.

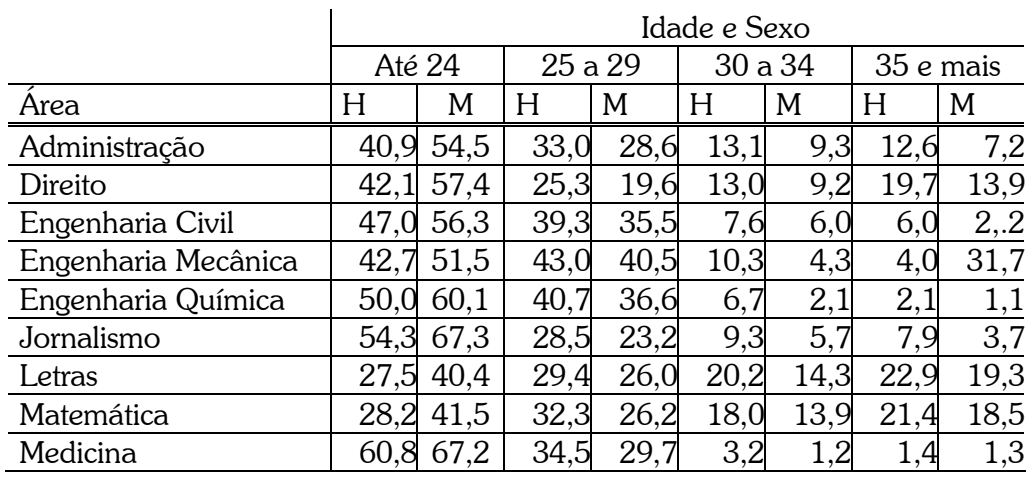

Fonte: DAES/INEP/MEC - ENC/99 (www.inep.gov.br, acionado 15/01/01 às 18:20h).

Porém, ao lado de encontrarmos uma proporção mais alta de mulheres mais jovens iniciando e concluindo o curso superior, encontramos, também, uma proporção maior de mulheres mais velhas (25 anos e mais) iniciando seu curso superior (Tabela 5). Isto parece indicar uma volta à escola mais intensa de mulheres que, por contingências da vida, teriam abandonado os estudos. Tal 
tendência parece presente, também, quando analisamos estudantes no supletivo. Com efeito, uma porcentagem ligeiramente superior de mulheres que de homens freqüentam cursos de educação supletiva: as mulheres representam $50,4 \%$ dos estudantes no supletivo de ensino fundamental e $51,4 \%$ no ensino médio. ${ }^{28}$ Isto poderia indicar seja a sobrerepresentação feminina na faixa etária concernida (razão de sexo), quanto uma busca ativa da educação pelas mulheres, evidenciada, também, por outro indicador: a porcentagem de estudantes freqüentando curso superior privado é ligeiramente superior entre as mulheres (Tabela 6). Baudelot e Establet ${ }^{29}$, ao interpretarem perfil similar entre estudantes franceses, se referem a um patamar superior de energia escolar entre as meninas e moças.

\section{Tabela 6}

Porcentagem de concluintes no sistema privado do ensino superior por tipo de curso e sexo. Brasil, 1999.

\begin{tabular}{l|c|c}
\multicolumn{1}{c|}{ Curso } & \multicolumn{2}{c}{ Sexo } \\
\hline \hline Administração & Homens & Mulheres \\
\hline Direito & 70,5 & 81,0 \\
\hline Engenharia civil & 48,4 & 80,7 \\
\hline Engenharia mecânica & 42,3 & 52,5 \\
\hline Química & 27,1 & 41,1 \\
\hline Jornalismo & 66,7 & 38,7 \\
\hline Letras & 42,4 & 73,8 \\
\hline Matemática & 45,3 & 52,2 \\
\hline Medicina & 35,9 & 42,8 \\
\hline Veterinária & 39,5 & 41,3
\end{tabular}

Fonte: ENC 1999.

${ }^{28}$ PNAD, 1999

${ }^{29}$ Baudelot, Christian e Establet, Roger. Allez les filles. Paris, Seuil, 1992. 
Políticas educacionais e gênero

Tabela 7

Porcentagem de mulheres freqüentando cursos de mestrado stricto sensu e doutorado por área do conhecimento. Brasil (1993-1994)

\begin{tabular}{|l|c|c|}
\hline \multirow{2}{*}{\multicolumn{1}{c|}{ Área do Conhecimento }} & \multicolumn{2}{c|}{ Nível } \\
\cline { 2 - 3 } & Mestrado & Doutorado \\
\hline Ciências Agrárias & 52,5 & 33,1 \\
\hline Ciências Biológicas & 68,5 & 60,4 \\
\hline Ciências Exatas e da Terra & 44,5 & 50,2 \\
\hline Ciências Humanas & 55,4 & 49,4 \\
\hline Ciências da Saúde & 49,0 & 36,7 \\
\hline Ciências Sociais Aplicadas & 48,4 & 52,8 \\
\hline Engenharias & 27,7 & 36,4 \\
\hline Lingüística, Letras e Artes & 69,5 & 64,6 \\
\hline TOTAL & 49,2 & 46,0 \\
\hline
\end{tabular}

Fonte: VelLOSO, Jaques e VelHO, Lea. Mestrandos e doutorandos no país: trajetórias de formação. Brasilia, CAPES/MEC, 2001, pp.36-37.

Nota: Dados relativos a amostra de mestrandos e doutorandos.

Destaco duas informações contidas na Tabela 7: a data a que se referem os dados (1993-1994), sendo possível que ao final da década a pequena subrepresentação das mulheres tenha diminuído; a pequena diferença entre mestrado e doutorado sugere que a passagem de nível escolar não parece constituir barreira ao acesso de mulheres. Evidentemente, seria possivel refinar a comparação se estivessem disponíveis informações para anos subsequentes que permitissem acompanhar o fluxo de homens e de mulheres da graduação para a pós-graduação.

Raramente, pesquisadores/as, militantes, administradores brasileiros/as vêm se perguntando qual o impacto da expansão $e$ das reformas educacionais contemporâneas na escolaridade de homens e mulheres. Procurei responder parcialmente a esta pergunta, admitindo, desde já, que se trata de um exercício preliminar, visando complexificar o simplismo triunfalista ou pessimista de muitos/as que têm escrito sobre educação das mulheres de uma perspectiva de gênero. Para esta análise foram 
Fúlvia Rosemberg

selecionados seis tópicos: a expansão do sistema escolar; a especialização em disciplinas e áreas de conhecimento; o magistério; as reformas curriculares; a política do livro didático e a educação infantil.

\section{A expansão do sistema}

Uma das metas fundamentais da atual administração no setor educacional é a expansão do sistema, ampliando a oferta. Para avaliar os impactos dessa expansão foram selecionados três indicadores - taxa de alfabetização, taxa de escolaridade (ou número de estudantes) e taxa de instrução - para os quais foram calculadas taxas de crescimento as quais foram comparadas, a seguir, à taxa de crescimento da população de mesma faixa etária (Tabela 8). A necessidade de controle das taxas de crescimento populacionais decorre dos diferenciais sexuais quanto à esperança de vida.

Analisando-se a Tabela 8, onde foram transcritas tais taxas de crescimento (ou a porcentagem da diferença entre 1999 e 1985), observa-se uma tendência peculiar, pouco referida na literatura: uma taxa de crescimento ligeiramente mais acentuada entre os homens de acesso ao sistema educacional (51,4\% e 50,2\% de taxa de crescimento 85-99 para estudantes homens e mulheres), porém uma progressão ou rentabilidade maior das mulheres no sistema de ensino, especialmente no nível superior (ver taxas de crescimento de estudantes no nível superior e de pessoas tendo pelo menos 12 anos de instrução).

Para averiguar se o sistema educacional brasileiro privilegiou um ou outro sexo, é necessário controlar-se a razão de sexo (porcentagem de mulheres na população na taxa de crescimento) no período considerado. No período 1985-1999, o crescimento da população feminina brasileira tendo 5 anos e mais superou o da masculina em três pontos percentuais (Tabela 8). Isto se deve à maior longevidade das mulheres, bem como à morte precoce de homens na juventude e nos primeiros anos da vida 
Políticas educacionais e gênero

adulta, especialmente por causas violentas. ${ }^{30}$ Seria possível levantar hipóteses, ou construir modelos explicativos que articulassem a ideologia de gênero constitutiva de nossa sociedade, o sistema educacional $e$ os diferenciais sexuais na esperança de vida. Apesar de desejável, isto ultrapassaria os limites desse trabalho.

Tabela 8

Taxas de crescimento (\% da diferença) entre 85-99 por indicadores educacionais selecionados e sexo. Brasil.

\begin{tabular}{l|r|r}
\hline \multicolumn{1}{c|}{ Indicadores } & \multicolumn{2}{|c}{ Taxa de crescimento* } \\
\hline \hline População (5 anos e mais) & Masculina & Feminina \\
\hline Total & 25,4 & 28,5 \\
\hline Urbana & 37,2 & 40,0 \\
\hline Rural & $-5,1$ & $-5,5$ \\
\hline Alfabetização (5 anos e mais) & \multicolumn{2}{|c}{} \\
\hline Total & 43,3 & 48,2 \\
\hline Urbana & 49,4 & 54,1 \\
\hline Rural & 19,8 & 23,0 \\
\hline Estudantes (5 anos e mais) & \multicolumn{3}{|c}{} \\
\hline Total & 51,4 & 50,2 \\
\hline Pré & 84,1 & 78,4 \\
\hline Fundamental & 34,9 & 28,9 \\
\hline Médio & 167,2 & 159,9 \\
\hline Superior & 69,9 & 123,4 \\
\hline Instrução (10 anos e mais) & 30,8 & 33,9 \\
\hline Total & $-15,9$ & $-18,8$ \\
\hline População sem instrução e até 1 ano & 8,2 & 9,9 \\
\hline 4 anos & 76,9 & 76,8 \\
\hline 8 anos & 102,2 & 133,3 \\
\hline 9 a 11 anos & 73,9 & 125,8 \\
\hline 12 anos e mais
\end{tabular}

Fonte: PNADs 85 e 99.

Nota: exclusive população rural da região Norte.

* \% de crescimento: total 1999 - total 1985/total menor X 100.

${ }^{30}$ LAURENTI, Ruy. Perfil epidemiológico da saúde masculina na região das américas. São Paulo, USP, 1998. 
Porém, é possível efetuar um exercício comparando o crescimento do número de estudantes com o crescimento da população na faixa de idade considerada. Assim procedendo, obtém-se uma proxi do controle do crescimento decorrente do aumento de população (Tabela 9).

Tabela 9

Crescimento (1985-1999) da população de 5 anos e mais freqüentando a escola por sexo. Brasil.

\begin{tabular}{|c|c|c|c|c|c|}
\hline \multicolumn{6}{|c|}{$\begin{array}{c}\text { Diferença (1985 - 1999) na população de } 5 \text { anos e } \\
\text { mais }\end{array}$} \\
\hline Sexo & $\begin{array}{c}\text { Total } \\
1 \\
\end{array}$ & $\%$ & $\begin{array}{c}\text { Freqüentando } \\
\text { a escola } 2\end{array}$ & $\%$ & $\begin{array}{l}\% \text { de } \\
2 / 1\end{array}$ \\
\hline "Homens & 214.344 .247 & 46,4 & 8.088 .234 & 49,9 & $\overline{56,4}$ \\
\hline Mulheres & 16.546 .565 & 53,6 & 8.113 .919 & 50,1 & 49,0 \\
\hline Total & 30.890 .812 & 100,0 & 16.202 .153 & 100,0 & 52,4 \\
\hline
\end{tabular}

Tais dados sugerem que o sistema educacional brasileiro estaria propiciando um acesso relativamente maior aos homens $e$ uma ascensão relativamente superior às mulheres. Tal tendência, se confirmada por outros estudos mais precisos (por exemplo, com base nos censos demográficos), deve ser atribuída às reformas educacionais por exemplo, aprovação automática, ciclos e classes de aceleração, associada à observação anteriormente efetuada (e que também deve ser aprofundada), de uma sobrerepresentação das mulheres na rede privada do ensino superior. Ou seja, há indícios, que deveriam ser mais profundamente estudados, de que as políticas públicas de educação no Brasil contemporâneo não estariam sendo igualitárias ou privilegiando as mulheres, como quis o informe nacional anteriormente referido. ${ }^{31}$

${ }^{31}$ BRASIL. MEC/INEP. EFA 2000... Op.cit. Estudo mais preciso deveria estar atento a faixas etárias específicas. 
Políticas educacionais e gênero

Esta análise evidenciou a necessidade urgente de disponibilidade de dados sobre matrícula nas diversas redes de ensino e nos diferentes níveis (incluindo superior), desagregadas por sexo, informações coletadas porém nem sempre processadas e divulgadas pelo MEC/INEP. Da mesma forma, seriam necessárias informações desagregadas por sexo e cor/raça sobre estudantes em trajetórias "inovadoras" (como classes de aceleração) ou incentivadas no período recente (como o turno noturno) para ampliar o acesso à educação $e$ atingir as metas internacionais. Temos fortes indícios de que a "clientela" privilegiada de classes de aceleração e curso noturno são adolescentes homens e negros. As questões que se colocam são: qual escolaridade está-se lhes oferecendo para entrarem ou permanecerem no sistema? Quantos progridem? Como progridem? O que aprendem? Que retornos podem ser esperados no mercado de trabalho, na vida privada $e$ no exercício de cidadania? Que especializações escolhem?

\section{Especializações femininas e masculinas}

Se as mulheres enfrentam barreiras menos acentuadas ou dispõem de maior energia que os homens para acenderem a níveis superiores de escolaridade, o sistema educacional brasileiro ainda apresenta tendência à segmentação sexual dos ramos de ensino. Isto é, uma vez dentro da escola, mulheres tendem a seguir cursos propedêuticos e homens cursos profissionais; no ensino superior ainda persiste uma certa polarização entre Letras, Ciências Humanas e Sociais, mais femininas; Ciências Exatas e Tecnológicas, mais masculinas.

Três tendências marcam a distribuição de homens $e$ mulheres pelos ramos de ensino: a diferenciação sexual tende a ocorrer tão precocemente quanto o sistema escolar permite; ela se mantém relativamente constante pelos níveis escolares; não se 
Fúlvia Rosemberg

notam indícios de que esta especialização sexual nas carreiras escolares tenha desaparecido ${ }^{32}$, apesar de sua atenuação.

De acordo com o Censo da Educação Profissional ${ }^{33}$, as mulheres representam apenas $39,3 \%$ dos/as alunos/as matriculados/as na Educação Profissional, isto é, em cursos direcionados ao mercado de trabalho. Além disso, nota-se uma segregação dos sexos pelas áreas do ensino profissional (Tabela 10).

Tabela 10

Matrículas na Educação Profissional por níveis, áreas e sexo. Brasil, 2000.

\begin{tabular}{l|l|l|l|l|l|l}
\hline Nível & Área & \multicolumn{3}{|c}{ Matrículas } & & \\
\cline { 3 - 7 } & & Total* & $\begin{array}{l}\text { Total } \\
\text { Ajustado** }\end{array}$ & Homens & Mulheres & $\%$ \\
\hline \hline \multirow{4}{*}{ Básico } & Total & 2.045 .234 & 1.909 .466 & 1.176 .143 & 733.323 & 38,4 \\
\cline { 2 - 7 } & Agropecuária & 59.686 & 53.952 & 42.119 & 11.833 & 21,9 \\
\cline { 2 - 7 } & Indústria & 485.454 & 466.566 & 376.317 & 90.249 & 19,3 \\
\cline { 2 - 7 } & Comércio & 82.907 & 81.797 & 69.267 & 12.530 & 15,3 \\
\cline { 2 - 7 } & Serviços & 1.417 .187 & 1.307 .151 & 688.440 & 618.711 & 47,3 \\
\hline \multirow{4}{*}{ Técnico } & Total & 716.652 & 673.764 & 376.415 & 297.349 & 44,1 \\
\cline { 2 - 7 } & Agropecuária & 55.914 & 50.976 & 42.383 & 8.593 & 16,8 \\
\cline { 2 - 7 } & Indústria & 178.209 & 172.448 & 136.775 & 35.673 & 20,7 \\
\cline { 2 - 7 } & Comércio & 3.434 & 3.388 & 2.087 & 1.301 & 38,4 \\
\cline { 2 - 7 } Tecno- & Serviços & 479.095 & 446.952 & 195.170 & 251.782 & 56,3 \\
\hline \multirow{4}{*}{ lógico } & Total & 97.249 & 96.221 & 64.440 & 31.781 & 33,0 \\
\cline { 2 - 7 } & Agropecuária & 625 & 625 & 453 & 172 & 27,5 \\
\cline { 2 - 7 } & Indústria & 26.713 & 26.493 & 21.153 & 5.340 & 20,1 \\
\cline { 2 - 7 } & Serviços & 69.911 & 69.103 & 42.834 & 26.269 & 38,0 \\
\hline
\end{tabular}

Fonte: MEC/INEP (2000 $)$.

* Incluindo os sem declaração de sexo.

** Incluindo apenas os com declaração de sexo.

${ }^{32}$ Rosemberg, Fúlvia \& Pinto, Regina P. A educação da mulher. São Paulo, CECF, Nobel, 1985.

33 Brasil. MEC/INEP. EFA 2000... Op.cit., p.1. 
Políticas educacionais e gênero

Os dados da tabela 10 mostram uma porcentagem inferior de matrículas femininas em todos os níveis e áreas da educação profissional, com exceção da área "serviço" no nível técnico (56,3\% de matrículas femininas). Porém, em todos os níveis, a área de serviço ocupa, sempre, a primeira posição nas matrículas femininas, em consonância com a configuração do mercado de trabalho, setor em que as mulheres se concentram. ${ }^{34}$

No ensino superior dispomos de informações não totalmente equiparáveis, sobre 1980 e 1999, na medida em que a denominação, o agrupamento das áreas de conhecimento se altera no transcorrer dos anos, bem como a unidade de análise: estudante ou concluintes (Tabela 11).

Tabela 11

Porcentagem de mulheres entre estudantes ou concluintes do ensino superior por áreas de conhecimento.

\begin{tabular}{l|c|c}
\hline \multicolumn{1}{c|}{ Áreas de conhecimento } & \multicolumn{2}{|c}{ Ensino Superior } \\
\hline \hline Ciências Biológicas e da Saúde & 1980 & $\begin{array}{c}1998 \\
\text { Estudantes } \\
\text { Concluintes }\end{array}$ \\
\hline $\begin{array}{l}\text { Ciências Exatas, da Terra } \\
\text { e Engenharia e Tecnologia }\end{array}$ & 18,6 & 68,9 \\
\hline Ciências Agrárias & 9,7 & 40,1 \\
\hline Ciências Humanas e Sociais & 53,8 & 37,9 \\
\hline Lingüística, Letras e Artes & 86,2 & 83,3 \\
\hline
\end{tabular}

Fonte: Censo 1980, apud Rosemberg, F. \& PinTo, R. P. A educação da mulher. Op. cit.; MEC/INEP (1998) apud CNDM/Conselho Nacional dos Direitos da Mulher. Indicadores de Gênero: educação. 2001, www.mi.gov.br/sedh/cndm.

Nota: Os dados originais foram agrupados e devem ser analisados com cautela.

${ }^{34} \mathrm{O}$ Programa Fundo de Amparo ao Trabalhador/FAT, do Ministério do Trabalho, apóia cursos de qualificação profissional. Não encontramos estatísticas recentes desagregadas por sexo, apenas a informação de que as mulheres representam entre $40 \%$ e $50 \%$ das matrículas nos cursos (www.mtb.gov.br. acionado em 18/08/01). 
Estes dados indicariam uma alteração acentuada da segregação sexual por áreas de conhecimento. A expansão do ensino superior não apenas estaria impulsionando o aumento de estudantes mulheres, e vice-versa, mas também sua opção por um leque maior de carreiras. Deve-se agregar a este comentário, a própria ampliação de ramos profissionais dentro de uma única carreira, o que também aumentaria o leque de opções. Veja-se, por exemplo, informações sobre os ENCs realizados nos últimos anos, que, desagregando mais as áreas de conhecimento, permitem observar a persistência, na década de 1990, de carreiras universitárias com predomínio masculino intenso (engenharias civil, elétrica, mecânica), outras com predomínio feminino (odontologia, jornalismo, letras, matemática) e outras tendendo ao equilîbrio (engenharia química, administração, direito, medicina veterinária). A tendência, então, mais parece ser de uma feminização de carreiras anteriormente masculinas do que viceversa, sendo necessário, porém, maior refinamento nos dados coletados.

Pesquisa recente comparou escolhas profissionais de meninos (156) e meninas (151) freqüentando a $4^{\mathrm{a}}$ série do ensino fundamental em Belo Horizonte a pesquisas anteriores (1929, 1944, 1993) equivalentes. As pesquisadoras detectaram mudanças e permanências relevantes: uma tendência, que permanece entre as meninas, é a da escolha de profissões liberais e de "cuidado"; uma outra que se altera refere-se à diminuição de escolhas por "professora e artista". ${ }^{35}$ Entre os meninos, atualmente, as escolhas recaem, em primeiro lugar, nas profissões de atleta e artista $e$ apenas em segundo lugar em profissões liberais (engenheiro $e$ advogado), invertendo a tendência observada anteriormente. Além da polarização precoce de carreiras, esses resultados indicam, também precocemente, expectativas de trajetórias escolares de duração diferente para meninos e meninas.

${ }^{35}$ LOURENÇO, Erika \& JinZENJI, Mônica Y. Ideais de crianças minerais no século $\mathrm{XX}$ : mudanças e continuidades. Psicologia: teoria e pesquisa, XV $16, \mathrm{n}^{\circ} 1$, janabr 2000, p.45. 
Políticas educacionais e gênero

Tabela 12

Porcentagem de graduandos presentes ao ENC/96-97-98-99, por áreas de conhecimento, ano e sexo. Brasil.

\begin{tabular}{|c|c|c|c|c|c|c|c|c|}
\hline \multirow[b]{2}{*}{$\begin{array}{c}\text { Áreas do } \\
\text { conhecimento }\end{array}$} & \multicolumn{4}{|c|}{ Homens } & \multicolumn{4}{|c|}{ Mulheres } \\
\hline & 1996 & 1997 & 1998 & 1999 & 1996 & 1997 & 1998 & 1999 \\
\hline Administração & 54,5 & 52,9 & 52,1 & 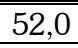 & 445,5 & 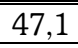 & $4 \overline{47,9}$ & 4 \\
\hline Direito & 51,6 & 50,4 & 49,1 & 48,7 & 48,4 & 49,6 & 50,9 & 51,3 \\
\hline Engenharia Civil & 73,2 & 72,9 & 75,5 & 75,0 & 26,8 & 27,1 & 24,5 & 25,0 \\
\hline Engenharia Química & & 56,8 & 57,3 & 57,6 & & 43,2 & 42,7 & 42,4 \\
\hline Medicina Veterinária & & 50,7 & 50,6 & 49,0 & & 49,3 & 49,4 & 51,0 \\
\hline Odontologia & & 37,4 & 36,7 & 37,6 & & 62,6 & 63,3 & 62,4 \\
\hline Engenharia Elétrica & & & 89,9 & 89,5 & & & 10,1 & 10,5 \\
\hline Jornalismo & & & 35,1 & 33,1 & & & 64,9 & 66,9 \\
\hline Letras & & & 13,6 & 14,1 & & & 86,4 & 85,9 \\
\hline Matemática & & & 39,3 & 40,1 & & & 60,7 & 59,9 \\
\hline Economia & & & & 55,3 & & & & 44,7 \\
\hline Engenharia Mecânica & & & & 95,4 & & & & 4,6 \\
\hline Medicina & & & & 54,9 & & & & 45,1 \\
\hline TOTAL & 54,6 & 51,8 & 46,1 & 47,8 & 45,4 & 48,2 & 53,9 & 52,2 \\
\hline
\end{tabular}

Fonte: DAES/INEP/MEC - ENC/99 (www.inep.gov.br, acionado 15/01/01 às $18: 20 \mathrm{~h})$.

As reformas educacionais contemporâneas introduziram, no Brasil, avaliações sistemáticas e abrangentes de competências escolares. Os resultados nestas avaliações apresentam alguma variação por sexo, em consonância com padrão de países desenvolvidos (por exemplo, EUA, Canadá e França) ${ }^{36}$ : as mulheres tendem a obter melhores resultados em provas de língua e os homens em matemática e ciências (Tabela 13). Tais resultados, porém, não são consistentes no transcorrer da vida escolar e devem ser interpretados com cuidado, pois, como vimos, a composição sócio-econômica, racial e etária do grupo de homens e mulheres, em dado ano escolar, não é a mesma.

${ }^{36}$ Ver: DuRu-Bellat, Marie. L'école des filles. Paris, L'Harmattan, 1990; BAUdELOT, C. e ESTABLET, R. Allez les filles. Op.cit. 
Fúlvia Rosemberg

Tabela 13

Desempenho no SAEB por série, disciplina e sexo. Brasil, 1999.

\begin{tabular}{l|l|l|l|c}
\multirow{2}{*}{ Disciplina } & \multicolumn{1}{|c|}{ Série } & Homens & Mulheres & $\begin{array}{c}\text { Diferença } \\
(\mathrm{M}-\mathrm{H})\end{array}$ \\
\cline { 3 - 5 } & & & & $+7,48$ \\
\hline \hline \multirow{3}{*}{$\begin{array}{l}\text { Língua } \\
\text { Portuguesa }\end{array}$} & $4^{\text {a } \text { Fundamental }}$ & 167,26 & 174,74 & $+10,91$ \\
\cline { 2 - 5 } & $8^{\circ}$ Fundamental & 227,16 & 238,07 & +10 \\
\cline { 2 - 5 } & $3^{\circ}$ Média & 260,36 & 271,06 & $+10,70$ \\
\hline \multirow{3}{*}{ Matemática } & $4^{\text {a } \text { Fundamental }}$ & 181,26 & 181,12 & $-0,14$ \\
\cline { 2 - 5 } & $8^{\circ}$ Fundamental & 252,88 & 240,82 & $-12,6$ \\
\cline { 2 - 5 } & $3^{\circ}$ Média & 289,37 & 274,42 & $-14,95$ \\
\hline
\end{tabular}

Fonte: Relatório SAEB 1999 (www.inep.gov.br, acionado 15/01/01, às 18:20h).

Em resumo: o sistema educacional brasileiro apresenta configuração semelhante, mas não igual, à de países desenvolvidos. De um lado, observamos progressão ligeiramente melhor das mulheres na escola associada à persistência de separação masculino-feminina entre os ramos de ensino; de outro, progressão escolar interrompida $e$ acidentada para mulheres $e$ homens de segmentos sociais e raciais subordinados.

Alterar o quadro da diferenciação sexual pelos ramos de ensino extrapola as políticas educacionais, pois sua configuração atual parece resultar, também, de padrões de socialização de gênero midiáticos, familiares, religiosos e dos pares além da forte segregação sexual do mercado de trabalho. Portanto, recomendações para o incentivo à formação profissional heterodoxa na escola, para homens e mulheres em contexto laboral tão intensamente segregado, será pouco eficiente se forem mantidas inalteradas as tendências das demais instâncias socializadoras e do mercado de trabalho. Por outro lado, a democratização do acesso à educação com qualidade constitui desafio para as políticas educacionais contemporâneas, desafio que passa, obrigatoriamente, pela valorização do magistério, atividade de gênero feminino e executada principalmente por mulheres. 
Políticas educacionais e gênero

\section{Magistério}

O sistema de ensino continua sendo uma ocupação feminina: sejam professoras, funcionárias ou especialistas, as mulheres representam mais de $80 \%$ da força de trabalho em educação. ${ }^{37} \mathrm{O}$ magistério continua sendo um dos principais nichos de inserção das mulheres no mercado de trabalho: em 1980 o magistério respondia por $8 \%$ de toda a PEA feminina ${ }^{38}$; em 1991 por $12 \%{ }^{39}$

A comparação intercensitária (1980-1991, Tabela 14) evidencia uma ligeira redução do percentual de mulheres no magistério $(1,2 \%)$ e uma ligeira redistribuição pelos níveis de ensino: pequena diminuição nos níveis de ensino pré-escolar e fundamental; aumento nos níveis médio e superior.

Tabela 14

Porcentagem de mulheres na PEA ocupada no magistério, por graus de ensino e ano. Brasil, 1980 e 1991.

\begin{tabular}{l|c|c}
\cline { 2 - 3 } & 1980 & 1991 \\
\hline \hline Magistério (Total) & 86,6 & 85,4 \\
\hline No ensino pré-escolar & 99,0 & 96,1 \\
\hline No ensino $1^{\circ}$ Grau (1 ${ }^{\mathrm{a}}$ a 4 ${ }^{\mathrm{a}}$ série) & 96,2 & 93,5 \\
\hline No ensino $1^{\circ} \mathrm{Grau}\left(5^{\mathrm{a}}\right.$ a $8^{\mathrm{a}}$ série) & 85,7 & 85,7 \\
\hline No ensino ${ }^{\circ}$ grau & 70,4 & 73,2 \\
\hline No ensino superior & 42,2 & 45,4 \\
\hline
\end{tabular}

Fontes: Censos 1980, 1991.

* Porcentagens de mulheres no total de cada grupo.

** Em 1970 inclui professores e auxiliares.

\footnotetext{
${ }^{37}$ BAtista, M. e Codo, Wanderley. Educação: carinho e trabalho. Op.cit., p.62.

${ }^{38}$ ROSEMBERG, F. Subordinação de gênero e alfabetização no Brasil. Op. cit.

${ }^{39}$ BRUSCHINI, Cristina. Trabalho das mulheres no Brasil: continuidades e mudanças no período 1985-1995. São Paulo, Fundação Carlos Chagas, 1998.
} 
Fúlvia Rosemberg

As pequenas mudanças entre 1980 e 1991 não alteraram, porém, a pirâmide: os homens estão subrepresentados nos níveis escolares que lidam com crianças e adolescentes $e$ superrepresentados no ensino superior, evidenciando forte discriminação de gênero (Tabela 15). Até a $4^{\text {a }}$ série do ensino fundamental exige-se do/a docente apenas formação em nível médio e seus salários são espetacularmente inferiores aos salários do/a docente do ensino superior.

Tabela 15

Porcentagem de mulheres no magistério (mercado formal) por tipos de especialidade e ano. Brasil, 1988 e 1998.

\begin{tabular}{|c|c|c|c|c|}
\hline \multirow{3}{*}{$\begin{array}{c}\text { Tipos de especialidade de } \\
\text { professores }\end{array}$} & \multicolumn{4}{|c|}{$\begin{array}{l}\text { Porcentagem de mulheres por } \\
\text { ano }\end{array}$} \\
\hline & \multicolumn{2}{|c|}{1988} & \multicolumn{2}{|c|}{1998} \\
\hline & $\mathrm{N}$ & $\%$ & $\mathrm{~N}$ & $\%$ \\
\hline Ensino pré-escolar & 269941 & 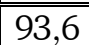 & 121355 & $\overline{994,8}$ \\
\hline Ensino especial & 5746 & 81,6 & 19169 & 88,0 \\
\hline Ensino fundamental & 133782 & 81,1 & 201088 & 80,2 \\
\hline Ensino $2^{\circ}$ grau/médio & 369602 & 72,4 & 449447 & 72,2 \\
\hline Disciplinas pedagógicas & 20674 & 44,8 & 17328 & 58,8 \\
\hline Formação profissional & 35758 & 46,0 & 59132 & 56,0 \\
\hline Ensino superior não classificado & 40339 & 37,3 & 49671 & 43,8 \\
\hline Ciências biológicas medicina & 18510 & 37,4 & 13652 & 43,6 \\
\hline Ciências humanas de ensino superior & 16990 & 43,1 & 17846 & 41,5 \\
\hline Ciências físicas e química & 3994 & 31,2 & 2791 & 38,3 \\
\hline Matemática, estatística & 4978 & 30,7 & 5229 & 36,1 \\
\hline Engenharia $e$ arquitetura & 10016 & 15,3 & 6596 & 23,5 \\
\hline Administ. econômicas e contábeis & 11396 & 19,5 & 8745 & 23,2 \\
\hline
\end{tabular}

Fonte: RAIS 1988 e 1998 apud Bruschini e Lombardi (www.fcc.org.br, acionado $15 / 01 / 01$ às $15: 00 \mathrm{~h}$ ). 
Políticas educacionais e gênero

De acordo com a RAIS $98^{40}$, o ensino pré-escolar continua sendo, no Brasil, a ocupação com maior percentual feminino (94,8\% de mulheres, Tabela 15). Porém, no magistério do ensino fundamental, ocorreu um pequeno declínio da participação feminina: de 94\% em 1978 para 91\% em 1999..1 Batista e Codo ${ }^{42}$ assinalam que a tendência a maior (ligeira) participação de homens entre profissionais da educação vem se intensificando nos últimos anos, em decorrência do desaparecimento progressivo de postos de trabalho no setor primário e do crescimento do setor secundário.

$\mathrm{O}$ mercado de trabalho do magistério mantém diferenças salariais entre os diferentes níveis de ensino e entre homens $e$ mulheres. Estas últimas tenderam, porém, a diminuir no período intercensitário (Tabela 16), decorrência possível da composição sexual por nível de ensino, da melhoria média da formação inicial da política salarial no sistema público e, possivelmente (a ser averiguado), o afluxo de aposentadorias em universidades públicas durante os anos 1990.

\section{Tabela 16}

Porcentagem de professores na PEA que recebem acima de 5 salários mínimos mensais por ano e sexo. Brasil, 1980 e 1991.

\begin{tabular}{l|c|c|c} 
Rendimento mensal & Ano & Homens & Mulheres \\
\cline { 2 - 4 } $\begin{array}{l}\text { acima de 5 salários } \\
\text { mínimos }\end{array}$ & 1980 & 51,4 & 14,3 \\
\cline { 2 - 4 } & 1991 & 38,7 & 13,7 \\
\hline
\end{tabular}

Fonte: Censos Demográficos 1980 e 1991.

\footnotetext{
40 apud BRUSCHINI, Cristina \& LOMBARDI, Maria R. Banco de dados sobre o trabalho das mulheres. www.fcc.org.br, 2001.

${ }^{41}$ PNADs apud PAES DE BARROS \& MENDONÇA. O mercado de trabalho para professores no Brasil. Brasília, IPEA, 2001.

${ }^{42}$ BAtistA, M. e CODO, Wanderley. Educação: carinho e trabalho. Brasília/ Petrópolis, UNB/Confederação Nacional dos Trabalhadores em Educação/ Vozes, 1998.
} 
Fúlvia Rosemberg

Para o magistério atuando em empresas que respondem aos critérios da RAIS, o diferencial de formação escolar e de salário entre os sexos sugere que, neste amplo campo profissional, convivem docentes com perfis muito diferenciados (Tabela 17).

A maioria das docentes mulheres prosseguiu escolaridade até o nível médio $(53,9 \%)$ e a maioria dos docentes homens prosseguiram-na até o ensino superior completo $(62,9 \%)$. Isto pode justificar, em parte, a diferença de rendimentos médios (7,41 e 5,08 , respectivamente) para homens e mulheres, respectivamente. Porém, mesmo no interior de cada nível de instrução da mesma profissão docente, o rendimento médio dos homens é superior ao das mulheres, apontando destinos diferentes para "estranhos nos ninhos": um teto invisível para as mulheres em carreiras masculinas; uma escada rolante invisível para os homens em carreiras femininas. Ora, quem define a condição masculina $e$ feminina das trajetórias docentes é a idade dos/as alunos/as. Mulheres são docentes de crianças; homens mais docentes de adultos. As reformas de ensino contemporâneas não atingiram o miolo dessas desigualdades estruturais.

\section{Tabela 17}

Docentes e rendimento, por sexo e nível de instrução. Brasil, 1999.

\begin{tabular}{|c|c|c|c|c|}
\hline \multirow[t]{2}{*}{ Instrução } & \multicolumn{2}{|c|}{ Homens } & \multicolumn{2}{|c|}{ Mulheres } \\
\hline & Instrução & $\begin{array}{l}\text { Rendi- } \\
\text { mento }\end{array}$ & Instrução & $\begin{array}{l}\text { Rendi- } \\
\text { mento }\end{array}$ \\
\hline Analfabeto & 0,4 & 4,20 & 0,6 & 3,61 \\
\hline $4^{\mathrm{a}}$ série incompleta & 0,6 & 3,40 & 0,7 & 2,69 \\
\hline $4^{\mathrm{a}}$ série completa & 0,9 & 3,60 & 1,2 & 2,31 \\
\hline $8^{\mathrm{a}}$ série incompleta & 1,0 & 3,43 & 1,6 & 2,68 \\
\hline $8^{\mathrm{a}}$ série completa & 4,0 & 6,35 & 5,2 & 4,99 \\
\hline Ensino Médio incompleto & 2,4 & 3,77 & 3,5 & 3,37 \\
\hline Ensino Médio Completo & 18,3 & 3,94 & 40,9 & 3,66 \\
\hline Educ. Superior Incompleta & 9,5 & 4,90 & 7,5 & 4,82 \\
\hline Educ. Superior Completa & 62,9 & 9,18 & 38,6 & 7,06 \\
\hline Total & 100,0 & 7,41 & 100,0 & 5,08 \\
\hline
\end{tabular}

Fonte: RAIS (1999) apudCNDM (2001). 
Políticas educacionais e gênero

Alguns estudos evidenciam as condições mais adversas para as mulheres que para os homens quando exercem a função docente: Batista e Codo ${ }^{43}$ referem-se ao grande número de professores/as acometidos/as de enfermidades profissionais; uma maior porcentagem de docentes mulheres que de homens trabalham em zona rural; o número de professoras leigas (sem qualificação profissional requerida) é superior ao de professores leigos. ${ }^{44}$

O salário dos/as professores/as, especialmente da educação infantil e do ensino fundamental, continua extremamente baixo, apesar do aumento decorrente do FUNDEF. De acordo com informe brasileiro para a Conferência de Dakar ${ }^{45}$, no ensino fundamental ocorreu, entre dezembro de 1997 e agosto de 1998, um aumento de $12,9 \%$ no salário dos/as professores/as, aumento que ascendeu a 49,6\% nas redes municipais do Nordeste. Tal aumento deve ser relativizado, pois seria necessário controlar o número de horas trabalhadas e a razão docente/aluno/a. Ou seja, é necessário verificar se o aumento correspondeu a maior valorização da profissão ou ao aumento da remuneração por aumento de trabalho. Há indicações, por exemplo, de aumento do número de alunos/as por professor/a no ensino fundamental. ${ }^{46}$

O Censo do Professor ${ }^{47}$ revelou, por sua vez, discriminações contra as mulheres no magistério, apesar de poucas informações terem sido publicadas desagregando a variável sexo. Em 1997 foram recenseados 1.617 .611 docentes trabalhando na educação básica brasileira, $85,7 \%$ dos quais eram mulheres. Sua remuneração média era $R \$ 378,67$, porém apresentando intensa variação em função da rede de ensino e da localização regional (Tabelas 18 e 19).

${ }^{43}$ BATISTA, M. e CODO, Wanderley. Educação: carinho e trabalho. Op.cit., p.63.

${ }^{44}$ Rosemberg, F. \& PinTo, R. P. A educação da mulher. Op.cit.

${ }^{45}$ Brasil. MEC/INEP. Censo do Ensino Profissional. Brasília, INEP, 2000.

${ }^{46} \mathrm{MEC} / \mathrm{INEP}$. EFA 2000 Educação para todos... Op.cit.

${ }^{47}$ MEC/INEP. Censo do Professor. 1997. Brasília, INEP, 1998. 
Fúlvia Rosemberg

\section{Tabela 18}

Taxa de participação feminina entre docentes da educação básica e média de salários por rede de ensino. Brasil, 1997.

\begin{tabular}{l|c|c}
\hline \multicolumn{1}{c|}{ Redes de Ensino } & \% de mulheres & Salário médio \\
\hline \hline Federal & 44,5 & $1.527,01$ \\
\hline Estadual & 84,7 & 584,56 \\
\hline Municipal & 89,8 & 378,67 \\
\hline Particular & 80,1 & 674,66 \\
\hline \multicolumn{2}{l}{ Fonte: MEC/INEP (1997). }
\end{tabular}

Nota-se, no ensino básico, que quanto maior a participação de mulheres entre os docentes, menor a média salarial (Tabela 18); nota-se, também, intensa diferenciação no salário médio em função dos níveis de ensino (quanto menor a idade do/a educando/a menor o salário do/a professor/a).

\section{Tabela 19}

Média de salários de docentes por região fisiográfica e nível de ensino.

Brasil, 1997.

\begin{tabular}{l|l|c|c|c}
\hline \multirow{2}{*}{ Região } & \multicolumn{4}{|c}{ Níveis de Ensino } \\
\cline { 2 - 5 } & $\mathrm{EI}^{*}$ & $\begin{array}{c}\mathrm{EF} \\
1^{\mathrm{a}} \text { a } 4^{\mathrm{a}}\end{array}$ & $\begin{array}{c}\mathrm{EF} \\
5^{\mathrm{a}} \text { a } 8^{\mathrm{a}}\end{array}$ & $\mathrm{EM}$ \\
\hline \hline Brasil & 419,48 & 425,60 & 605,41 & 700,19 \\
\hline Norte & 322,01 & 360,77 & 586,37 & 735,46 \\
\hline Nordeste & 195,00 & 231,17 & 372,41 & 507,82 \\
\hline Sudeste & 587,00 & 613,97 & 738,57 & 772,09 \\
\hline Sul & 464,96 & 460,12 & 594,44 & 683,03 \\
\hline Centro-Oeste & 573,64 & 447,55 & 584,20 & 701,79 \\
\hline
\end{tabular}

Fonte: MEC/INEP (1997).

* EI: Educação pré-escolar e classe de alfabetização.

Pode-se, pois, concluir que a manutenção de salários tão baixos para os/as professores/as da educação infantil e do ensino fundamental (que ocupam $3,6 \%$ da força de trabalho formal feminina) contribui para manter o intenso diferencial nos 
Políticas educacionais e gênero

rendimentos de trabalhadoras mulheres brasileiras. Esta é, sem dúvida, uma tendência de discriminação de gênero que permanece no sistema educacional brasileiro e para a qual pouca, ou nenhuma, atenção foi dada na agenda internacional sobre educação nos anos 1990: enquanto nicho importante do mercado de trabalho feminino, o sistema educacional, público e privado, produz discriminação de gênero, ao desqualificar profissões associadas ao feminino e executadas principalmente por mulheres. Por outro lado, aceita, sustenta e cria profunda desigualdade de idade: as crianças pequenas são penalizadas por serem educadas por docentes menos qualificados/as e que recebem piores salários.

O magistério constitui um caso exemplar, mas não isolado, de discriminação de gênero que persiste no mercado de trabalho associada a educação. A despeito do aumento notável dos níveis de escolaridade das mulheres e de seu impacto na melhoria do nível de escolaridade da População Economicamente Ativa/PEA, o rendimento das mulheres continua inferior ao dos homens para mesmo nível educacional. ${ }^{48}$ Além disso, como afirmei, seria necessário abrir o baú do mercado da educação e analisar o diferencial salarial masculino e feminino dos que aí trabalham. De posse de tais informações, poderíamos ampliar a reflexão sobre quem vem arcando com os custos da expansão da educação tal como vem sendo realizada.

\section{Reformas educacionais e agenda do movimento de mulheres/ feminista}

O Programa Nacional de Direitos Humanos ${ }^{49}$ e as reformas educacionais dos anos 1990 acolheram três itens antigos da agenda do movimento de mulheres/feministas brasileiro no plano da educação, com impactos variáveis: a inclusão de

${ }^{48}$ BRuschini, C. \& Lombardi, M. R. Banco de dados sobre o trabalho das mulheres. Op.cit.

${ }^{49}$ Brasil, Presidência da República. Programa Nacional de Direitos Humanos. Brasília, Presidência da República, Ministério da Justiça, 1996. 
Fúlvia Rosemberg

educação/orientação sexual no currículo escolar; o combate ao sexismo no currículo escolar, especialmente nos livros didáticos; a expansão da educação infantil como forma de cuidado $e$ educação da prole da mãe trabalhadora.

\subsection{Alterações curriculares}

Um pouco antes da divulgação do Programa Nacional de Direitos Humanos, dia 8 de março 1996, o MEC e o Ministério da Justiça, através do Conselho Nacional dos Direitos da Mulher/ $\mathrm{CNDM}$, celebraram um protocolo de igualdade de direitos entre homens e mulheres. ${ }^{50}$

O protocolo celebra que:

Os Ministérios da Justiça e da Educação se obrigam a colaborar no sentido de assegurar que o processo educativo se constitua em instrumento eficaz para combater todas as formas de discriminação contra as mulheres, promovendo o reconhecimento de sua dignidade, igualdade e de sua cidadania plena. A efetivação do compromisso se traduziu em duas linhas de ação a serem desenvolvidas pelo MEC: I) incorporar à programação curricular da TV Escola, temas que promovam o reconhecimento de igualdade de direitos entre homens e mulheres, II) considerar como um dos critérios para a seleção de livros didáticos a serem adquiridos $e$ indicados para as escolas de primeiro $e$ de segundo graus, o conteúdo não discriminatório em relação à mulher. ${ }^{51}$

O acompanhamento da concretização da primeira ação do protocolo constitui tarefa ainda a ser realizada. Porém, o MEC, em certo sentido, ultrapassou os limites desse compromisso ao incluir nos Parâmetros Curriculares Nacionais para o Ensino

${ }^{50}$ BeISIEgel, Celso R. Uma cultura para a democracia. São Paulo. FEUSP, mimeo., s/d.

${ }^{51}$ BRASIL, PRESIDÊNCIA DA REPÚBLICA, 1996 apud ID., IB., p.17. 
Políticas educacionais e gênero

Fundamental a Orientação Sexual entre os temas transversais. ${ }^{52}$ É no capítulo referente à Orientação Sexual que foram dedicadas três páginas ao bloco de conteúdos sobre Relaçóes de Gênero, apesar desta questão ser tratada de passagem em outros dos temas transversais (como no tema Trabalho e Consumo).

Aqui também resta efetuar uma análise sobre as ênfases que transparecem no tema da Orientação Sexual. O compromisso declarado com a formação para a cidadania, o respeito à diversidade transparecem na Introdução aos PCNs quando se afirma que o ensino fundamental deve preparar o/a aluno/a para posicionar-se "contra qualquer discriminação baseada em diferenças culturais, de classe social, de crenças, de sexo, de etnia ou outras características individuais e sociais". ${ }^{53}$

Apesar de criticado - por exemplo, a tendência a valorizar modelo heterossexual de família e sexualidade ${ }^{54}-$, os PCNs introduzem, a meu ver pela primeira vez nacionalmente, uma visão laica de educação sexual para os/as alunos/as do ensino fundamental. Lastima-se que este recorte não tenha sido adotado nos demais níveis de ensino ${ }^{55}$.

A política do livro didático foi outro tópico tratado. Para Beisiegel,

a Secretaria de Educação Fundamental do Ministério da Educação encontraria no Programa Nacional do Livro

\footnotetext{
${ }^{52}$ Os demais foram: Ética, Pluridade Cultural, Meio Ambiente, Saúde, Trabalho e Consumo. BRASIL. MEC. Parâmetros Curriculares Nacionais: terceiro e quarto ciclos do ensino fundamental. Brasília, MEC/SEF, 1998.

${ }^{53}$ BRASIL, MEC. Parâmetros Curriculares Nacionais Temas Transversais $-3^{\circ}$ e $4^{\circ}$ ciclos do Ensino Fundamental. Brasília, MEC, 1998.

${ }^{54}$ AuAD, Daniela. Gênero e Educação. In: SOF (org.) Cadernos Sempre Viva, 1999, p.25-39.

${ }^{55} \mathrm{O}$ contraste com o debate anterior, sobre educação sexual na escola é notável. Ver Rosemberg, F. Educação sexual na escola. Cadernos de Pesquisa, nº 53 , 1985, pp.11-19; e ROSEMBERG, F. et alii. Educação formal da mulher: bibliografia e estado da arte. Brasília, REDUC/MEC, 1991.
} 
Fúlvia Rosemberg

Didático (PNLD) um dos principais instrumentos de implementação das orientações [sobre educação democrática] então fixadas nos Parâmetros Curriculares Nacionais. ${ }^{56}$

O combate ao sexismo no livro didático foi um dos pontos mais enfatizados pela agenda do movimento de mulheres/ feminista brasileiro nos anos 1970 e 1980, estimulando um bom número de pesquisas: Esmeralda Negrão e Tina Amado ${ }^{57}$ localizaram 44 títulos de pesquisa tratando, direta ou indiretamente, do tema.

De uma forma constante, tais estudos evidenciam que os livros didáticos, no período (até 1989), tendiam a criar e recriar uma imagem estereotipada de homens e mulheres em acordo com uma visão tradicional dos gêneros, reservando aos homens a esfera pública em todas as suas conotações (trabalho, lazer, espaço externo, atividade, riqueza e poder) e às mulheres a esfera privada (reprodução, espaço interno, passividade). Alguns estudos evidenciaram, também, que estes estereótipos tendiam a ser mais intensos ao caracterizarem personagens de outros segmentos raciais.

As pesquisas sobre estereótipos em livros didáticos foram realizadas objetivando a explicitação e denúncia de discriminação de gênero; desempenharam uma função explicativa na argumentação sobre manutenção de comportamentos tradicionais e passivos entre as mulheres; algumas raras $^{58}$ contribuíram para avançar o conhecimento sobre a escola e muitas delas serviram como ponto de apoio para sensibilização do magistério quanto ao que se vem denunciando no Brasil sob a expressão da "educação diferenciada".

${ }^{56}$ BeISIEGEL, C. R. Uma cultura para a democracia. Op.cit., p.18.

${ }^{57}$ Negrão, Esmeralda \& AMADO, Tina. A imagem da mulher no livro didático. Tectos, n 2, São Paulo, FCC, 1989.

${ }^{58}$ Como a de PINTO, Regina. O livro didático... Op.cit. 
Políticas educacionais e gênero

Este amplo uso de resultados de pesquisa sobre sexismo em livros didáticos através de sua divulgação oral e escrita via debates, palestras, artigos na grande imprensa, programas de televisão, que ocorreu durante quase toda a década de 80 , pode ser atribuída à assimilação imediata de seu conteúdo, pois o livro é o material pedagógico mais usualmente empregado pelo magistério, e ao caráter semi-caricato dos estereótipos veiculados pelos materiais brasileiros. Possivelmente, ocorre uma forma de identificação distanciada do público feminino com os estereótipos descritos - o que aparece nos livros é próximo e distante da própria experiência de mulher -, o que gera adesão suficiente para manifestar indignação. Organismos oficiais, como os Conselhos da Condição Feminina, os órgãos compradores e distribuidores de livros (como a então FLE, e a atual FDE, em São Paulo), Secretarias Estaduais e Municipais de Educação organizaram seminários e materiais críticos sobre a questão (Pernambuco, 1989). Apesar disto, no nível da pesquisa, permaneceram algumas lacunas: o uso que fazem deste material professores/as e alunos/as; as dificuldades de criação de material alternativo e o que isto significa na sociedade brasileira; as formas de utilização contracorrente destes produtos sexistas, as implicações do fato de o Estado ser hoje, no Brasil, o maior comprador de livro didático.

O tema parece ter se esgotado nos anos 1990, sendo raras ou inexistentes as pesquisas em perspectiva diacrônica, visando captar transformações nas discriminações de gênero no material didático, apesar da importância, na atual administração, do Programa Nacional do Livro Didático/PNLD.

Se nos faltam pesquisas atualizadas sobre o sexismo em material didático, Escanfella e colaboradores ${ }^{59}$ analisaram livros de literatura infanto-juvenil em perspectiva diacrônica, visando captar transformações da ótica das relações de gênero, raça e idade. A

${ }^{59}$ ESCANFELLA e colaboradores. Literatura infantil e Ideologia. São Paulo, PUCSP, mimeo, 2001 
pesquisa mencionada teve por objetivo apreender permanências $e$ mudanças na construção de personagens que vivem histórias narradas em amostra de livros infanto-juvenis brasileiros contemporâneos (1975-1995) quando comparada a estudo anterior que analisara livros publicados entre 1990 e 1975. Em ambos estudos, o foco de análise das personagens foi a discriminação de gênero, raça e idade. Apoiando-se no referencial teórico proposto por John B. Thompson para analisar construções ideológicas, a pesquisa comportou duas fases: analisar atributos de 1800 personagens encontrados em 60 histórias contidas em 41 livros infanto-juvenis brasileiros publicados pela primeira vez entre 1975 e 1995; comparar alguns indicadores selecionados aos resultados da pesquisa anterior que analisara 168 livros publicados entre 1950 e 1975.

Destacando, apenas, as discriminações sexuais, observou-se que a configuração geral de ambas pesquisas é muito próxima, não ocorrendo, no período, mudança no perfil geral de representação de personagens masculinos e femininos: os masculinos são sempre mais freqüentemente representados, continuam assumindo posição relativa de destaque no plano ficcional e social; personagens femininos assumem posição relativa de destaque nas relações familiares. Porém, notou-se uma diminuição da intensidade das discriminações.

Beisiegel, ao analisar os pareceres de avaliações dos livros didáticos efetuados pelo MEC no bojo da atual política do PNLD, além de constatar a seriedade do trabalho realizado pelas equipes de especialista, informa o pequeno número de apreciações e descartes em decorrência de preconceitos e estereótipos e conclui:

ressalvados as poucas exceções já apresentadas, os pareceres do PNLD, nos itens sobre etnia e gênero retornam aos pontos de partida da análise de livros didáticos nas décadas de 50 a 60, lembrando-se à captação das manifestações específicas dos fenômenos observados. ${ }^{60}$

${ }^{60}$ BeISIEGEL, Celso R. Uma cultura para a democracia. Op.cit., p.29. 
Políticas educacionais e gênero

Ou seja, discriminações menos explícitas não são captadas na atual prática de avaliação do MEC e que implantou o protocolo de intenções anteriormente mencionado.

Deve-se notar, também, que pesquisas e intervenções neste campo incidem mais sobre a educação básica, deixando a descoberta a extensa produção editorial para o ensino superior.

Nada se sabe sobre dinâmica de gênero no extenso e rico mercado editorial que se criou para e em torno da expansão do sistema de ensino e da ênfase do livro didático como instrumento de melhoria da qualidade da educação. Questão crucial nos tempos atuais.

\subsection{Educação infantil}

A educação infantil entrou desde cedo na pauta do movimento de mulheres/feminista brasileiro como alternativa de "guarda" complementar aos cuidados maternos, particularmente através da reivindicação por creches.

A década de 1990 pode ser dividida em dois subperíodos: o primeiro até 1996, quando se nota intensa movimentação da sociedade brasileira no sentido de legitimação deste nível educacional; o segundo corresponde a recentes reformulações de prioridades nacionais focalizadas no ensino fundamental, o que acarretou uma estagnação na Educação Infantil.

No plano da legislação merecem destaque a Constituição de 1988 e a LDB/96. Foi a Constituição de 1988 que, pela primeira vez na história brasileira, reconheceu à criança pequena o direito à educação extra-familiar consubstanciado em atendimento em creches e pré-escolas. A LDB/96 inclui, também, pela primeira vez na história brasileira, as creches no sistema de ensino. Assim, creches e pré-escolas passaram a ser regulamentadas pela administração educacional; definiram-se seus objetivos, estabeleceram-se referenciais curriculares, especificou-se a formação mínima para seus profissionais, bem como a parte que lhes deve ser reservada nos orçamentos municipais $e$ as metas que lhes concerne no Plano Nacional de Educação. 
Apesar de problemas sérios nas estatísticas educacionais sobre este nível de ensino ${ }^{61}$, observa-se um aumento significativo das matrículas no período de 1986-2000, que passaram de 4.177.302 em 1986 para 6.012.240 em 2000 (43,9\% a mais).

O significado desse aumento espetacular deve ser nuançado, na medida em que se observou a manutenção de um forte contingente de professores/as leigos/as atuando em educação infantil (Tabela 20).

Tabela 20

Funções docentes em educação infantil tendo formação inferior ao ensino médio completo. Brasil, 1986 e 2000.

\begin{tabular}{|c|c|c|c|}
\hline \multicolumn{2}{|c|}{1986} & \multicolumn{2}{|c|}{2000} \\
\hline \multicolumn{2}{|c|}{$\begin{array}{c}\text { Pré-escola e classe de } \\
\text { alfabetização }\end{array}$} & \multicolumn{2}{|c|}{$\begin{array}{c}\text { Creche, pré-escola e classe de } \\
\text { alfabetização }\end{array}$} \\
\hline $\mathrm{N}$ & $\%$ & $\mathrm{~N}$ & $\%$ \\
\hline 48.269 & 27,5 & 320.841 & 13,0 \\
\hline
\end{tabular}

Observou-se, também, que a prioridade absoluta acordada ao ensino fundamental pela atual administração (período 19951999), interrompeu o ritmo de expansão do período anterior. Além disso, avaliações de custo aluno anual têm evidenciado a permanência de um hiato intenso entre o custo de uma criança na educação infantil (US\$10791) por ano e no ensino superior (US\$ 820) por ano. ${ }^{62}$

\footnotetext{
${ }^{61}$ As dificuldades decorrem de duas particularidades: a existência de uma rede "clandestina" de creches e pré-escolas não incorporadas aos cadastros das Secretarias de Educação; a inclusão apenas em 1995 das crianças de 0 a 4 anos nos quesitos sobre instrução/educação dos questionários utilizados pelo IBGE ROSEMBERG, F. Expansão da educação infantil e processos de exclusão. Op.cit.

${ }^{62}$ OCDE. Regards sur L'Éducation les Indicateurs de L'OCDE. Edition 2000. Paris, OCDE, 2000, p.23.
} 
Políticas educacionais e gênero

Isto é, tal diferença de custo aluno sustenta, cria e reproduz desigualdades estruturais de gênero e de idade: as crianças menores não merecem melhores condições educacionais porque, próximas da natureza, necessitam apenas de atenção de outros seres próximos à natureza (as mulheres).

\section{Post-Facio}

Evidentemente este artigo deveria ser amparado $e$ complementado por síntese teórica que procurasse articular teorias feministas e educacionais.

Tal não foi meu escopo, aqui, pois preferi destacar tendências dominantes e ambíguas da empiria. Durante o ano de 2001 produzi uma série de artigos, alguns publicados, outros no prelo $^{63}$, em que procurei apontar $e$ interpretar descompassos na produção de conhecimentos entre os campos da Educação $e$ dos Estudos sobre mulheres/feministas/de gênero. Nesta perambulação, fui apreendendo o profundo desconhecimento sobre a situação de homens e mulheres e sobre as dinâmicas do masculino $e$ do feminino no sistema educacional além de equívocos de interpretação compartilhados, infelizmente, por correntes progressistas e conservadoras, por exemplo, por tendências do Movimento de Mulheres e pelo Banco Mundial.

$\mathrm{O}$ medo do enfrentamento de ambigüidades e contradições tem propiciado interpretações sobre a escolaridade de homens e mulheres que essencializam a diferença, obnubilando, a meu ver, a interpretação de caminhos complexos da dominação estrutural e ideológica de gênero, constitutiva das sociedades contemporâneas. ${ }^{64}$

${ }^{63} \mathrm{O}$ que justifica a auto referência bibliográfica, ROSEMBERG, Fúlvia. Educação formal, mulher e relações de gênero... Op.cit.; e Caminhos cruzados: educação e gênero na produção acadêmica. Educação e Pesquisa, vol. 27, n 1 , 2001, pp.47-68.

${ }^{64}$ ROSEMBERG, F. Educação formal, mulher e relações de gênero... Op.cit. 
Fúlvia Rosemberg

Penso ter revelado aos Cadernos Pagu, neste artigo, meu pulo de gata para sair da armadilha: ampliar a agenda de pesquisas e estudos para além do espaço escolar. Aí, talvez, consigamos perceber novos processos de dominação de gênero... de classe, de raça e de idade. 